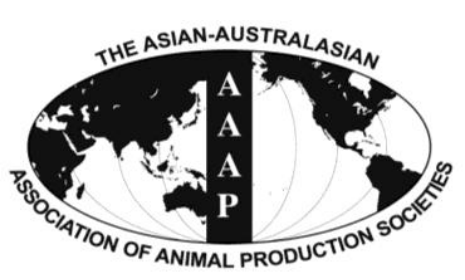

Open Access

Asian Australas. J. Anim. Sci.

Vol. 28, No. 8 : 1163-1170 August 2015

http://dx.doi.org/10.5713/ajas.14.0780

www.ajas.info

pISSN 1011-2367 elSSN 1976-5517

\title{
Optimizing Production of Two Potential Probiotic Lactobacilli Strains Isolated from Piglet Feces as Feed Additives for Weaned Piglets
}

\author{
Ming-Lun Chiang ${ }^{1}$, Hsi-Chia Chen ${ }^{2}$, Kun-Nan Chen ${ }^{3}$, Yu-Chun Lin ${ }^{4}$, Ya-Ting Lin, and Ming-Ju Chen* \\ Department of Animal Science and Technology, National Taiwan University, Taipei 10672, Taiwan
}

\begin{abstract}
Two probiotic strains, Lactobacillus johnsonii $\mathrm{x}-1 \mathrm{~d}-2$ and Lactobacillus mucosae $\mathrm{x}-4 \mathrm{w}-1$, originally isolated from piglet feces, have been demonstrated to possess antimicrobial activities, antibiotic resistances and interleukin-6 induction ability in RAW 267.4 macrophages in our previous study. These characteristics make L. johnsonii $\mathrm{x}-1 \mathrm{~d}-2$ and L. mucosae $\mathrm{x}-4 \mathrm{w}-1$ good candidates for application in feed probiotics. In this study, soybeal meal, molasses and sodium acetate were selected to optimize the growth medium for cultivation of $L$. johnsonii $\mathrm{x}-1 \mathrm{~d}-2$ and $L$. mucosae $\mathrm{x}-4 \mathrm{w}-1$. These two strains were then freeze-dried and mixed into the basal diet to feed the weaned piglets. The effects of $L$. johnsonii $\mathrm{x}-1 \mathrm{~d}-2$ and $L$. mucosae $\mathrm{x}-4 \mathrm{w}-1$ on the growth performance and fecal microflora of weaned piglets were investigated. The results showed that the bacterial numbers of $L$. johnsonii $\mathrm{x}-1 \mathrm{~d}-2$ and $L$. mucosae $\mathrm{x}-4 \mathrm{w}-1$ reached a maximum of 8.90 and $9.30 \log \mathrm{CFU} / \mathrm{mL}$, respectively, when growing in optimal medium consisting of 5.5\% (wt/vol) soybean meal, $1.0 \%(\mathrm{wt} / \mathrm{vol})$ molasses and $1.0 \%(\mathrm{wt} / \mathrm{vol})$ sodium acetate. The medium cost was $96 \%$ lower than the commercial de Man, Rogosa and Sharpe medium. In a further feeding study, the weaned piglets fed basal diet supplemented with freeze-dried probiotic cultures exhibited higher $(\mathrm{p}<0.05)$ body weight gain, feed intake, and gain/feed ratio than weaned piglets fed basal diet. Probiotic feeding also increased the numbers of lactobacilli and decreased the numbers of $E$. coli in the feces of weaned piglets. This study demonstrates that $L$. johnsonii x-1d-2 and L. mucosae x-4w-1 have high potential to be used as feed additives in the pig industry. (Key Words: Lactobacillus johnsonii, Lactobacillus mucosae, Soybean Meal, Molasses, Sodium Acetate, Weaned Piglet)
\end{abstract}

\section{INTRODUCTION}

Antibiotics are widely used to promote growth, prevent diarrhea, gastroenteritis and many diseases in animal agriculture, while some antibiotics have been shown to cause harm in human and animal health (Casewell et al., 2003). Presently, the demand of using natural and inexpensive antimicrobials for safe animal products continues to increase. The use of probiotics such as

\footnotetext{
* Corresponding Author: Ming-Ju Chen. Tel: +886-2-33664169, Fax: +886-2-27324070, E-mail: cmj@ntu.edu.tw

${ }^{1}$ Department of Tourism and Hospitality, Kainan University, Taoyuan 33857, Taiwan.

${ }^{2}$ Council of Agriculture, Executive Yuan, Taipei 10014, Taiwan.

${ }^{3}$ Department of Mechanical Engineering, Tungnan University, Taipei 22202, Taiwan.

${ }^{4}$ Livestock Research Institute, Council of Agriculture, Executive Yuan, Tainan 71246, Taiwan.

Submitted Oct. 7, 2014; Revised Dec. 10, 2014; Accepted Jan. 26, 2015
}

Lactobacillus, Bifidobacterium and Bacillus spp. in livestock feed has been reported to maintain or improve animal growth performance and intestinal microbial balance (Flint and Garner, 2009). It is feasible to use probiotic microorganisms as alternatives to antibiotics.

Indigenous gut microflora stabilizes in the gut and quickly propagates to a very stable population. The stable flora in the intestine could help the animal to resist infections. Several studies have shown that certain lactobacilli strains have the ability to interfere with the adherence and growth of pathogenic bacteria, reduce bacterial translocation (Berg, 1995) and intestinal inflammation (Chen et al., 2012). Therefore, isolation from suitable habitats, in vitro characterization, high levels of viable microorganisms, survival in the host, and inhibition of pathogen growth are very important for selecting potential strains applied in farm animal (Meng et al., 2010).

Lactobacillus johnsonii and Lactobacillus mucosae are anaerobic, Gram-positive, rod-shaped, non-sporogenic, and 
lactic acid-producing bacteria, which can be found in human and animal gastrointestinal tract as well as in some fermented foods (Roos et al., 2000; Pridmore et al., 2004). Both lactobacilli have been shown to exhibit probiotic effects, including epithelial attachment, pathogen inhibition and intestinal immunomodulation (Pridmore et al., 2004; Watanabe et al., 2010; Lee et al., 2012). However, only a few studies have demonstrated the beneficial use of $L$. johnsonii in the livestock and poultry industries. Casey et al. (2004) showed that L. johnsonii 4 may have the potential to reduce Salmonella invasion of intestinal epithelium in pigs. La Ragione et al. (2004) observed that the administration of L. johnsonii FI9785 helped control endemic necrotic enteritis caused by Clostridium perfringens in chickens. Further, no studies have yet addressed the value of $L$. mисоsae in animal production.

In our previous study, two probiotic strains, L. johnsonii $\mathrm{x}-1 \mathrm{~d}-2$ and $L$. mucosae $\mathrm{x}-4 \mathrm{w}-1$, originally isolated from piglet feces, have been demonstrated to possess antimicrobial activity against Escherichia coli, antibiotic resistances to doxycycline, lincomycin, oxytetracycline, and streptomycin, and interleukin (IL)-6 induction ability in RAW 267.4 macrophages (M. J. Chen, unpubl. data). These characteristics make $L$. johnsonii $\mathrm{x}-1 \mathrm{~d}-2$ and $L$. mucosae $\mathrm{x}-$ $4 \mathrm{w}-1$ the good candidates for application in feed probiotics. The providing of probiotic strains with competitive price and evidence of animal study may offer a series of industrial advantages. Thus, in the present study, we optimized the growth medium for cultivation of $L$. johnsonii $\mathrm{x}-1 \mathrm{~d}-2$ and $L$. mucosae $\mathrm{x}-4 \mathrm{w}-1$ with low-cost materials by response surface methodology (RSM) and sequential quadratic programming (SQP). Additionally, the effects of administration of freeze-dried probiotic lactobacilli on the growth performance and fecal microflora of weaned piglets were further investigated.

\section{MATERIALS AND METHODS}

\section{Bacterial strains}

Two strains of Lactobacillus spp. (L. johnsonii x-1d-2 and $L$. mисоsae $\mathrm{x}-4 \mathrm{w}-1)$ were obtained from Livestock Research Institute, Council of Agriculture, Executive Yuan (Tainan, Taiwan). L. johnsonii $\mathrm{x}-1 \mathrm{~d}-2$ and L. mucosae $\mathrm{x}-4 \mathrm{w}-$ 1 were originally isolated from feces of LandracexDuroc crossbred piglets at $1 \mathrm{~d}$ and $4 \mathrm{wks}$, respectively. These strains have been previously identified by $16 \mathrm{~S}$ rDNA sequence analysis and found to be tolerant to $\mathrm{pH} 3.0$ and $0.2 \%(\mathrm{wt} / \mathrm{vol})$ bile salts in the preliminary tests (M. J. Chen, unpubl. data). Before the experiments, each strain was inoculated $(1.0 \%, \mathrm{vol} / \mathrm{vol})$ and subcultured twice in lactobacilli de Man, Rogosa and Sharpe (MRS) broth (BD Difco, Sparks, MD, USA) at $37^{\circ} \mathrm{C}$ for $16 \mathrm{~h}$.

\section{Experimental design using response surface methodology and sequential quadratic programming \\ Soybean meal (Central Union Oil Corp., Taichung,} Taiwan), molasses (Taiwan Sugar Corp., Tainan, Taiwan) and sodium acetate (Echo Chemical Co., Ltd., Miaoli, Taiwan) were used as the main variables influencing the growth of lactobacilli in this study. A Box-Behnken design (BBD) (Box and Behnken, 1960) for these three variables with different coded levels (low, middle and high) was used to determine the optimized conditions for production of $L$. johnsonii $\mathrm{x}-1 \mathrm{~d}-2$ and $L$. mucosae $\mathrm{x}-4 \mathrm{w}-1$. The growth of lactobacilli strains was measured in duplicate under different levels of the three variables after incubation at $37^{\circ} \mathrm{C}$ for $16 \mathrm{~h}$. Seventeen combinations and the average values of the observed responses are shown in Table 1. The responses, as linear, two-factor interaction (2FI), quadratic and cubic models with the variables, were tested for adequacy and fitness using model analysis and lack-of-fit test. The model analysis compared the validities of various models for the response according to their F-values and a model with $\mathrm{p}$-values $(\mathrm{p}>\mathrm{F})$ below 0.05 was regarded as significant. The highest-order significant polynomial regression model was selected. The lack-of-fit test, measuring the fitness of the model obtained, compared the residual and pure errors at replicated design points. A model with no significant lack-of-fit was selected. Based on BBD, the polynomial model with undetermined coefficients for predicting the optimal condition is shown as follows:

$$
\begin{aligned}
& Y=\beta_{0}+\beta_{1} X_{1}+\beta_{2} X_{2}+\beta_{3} X_{3}+\beta_{12} X_{1} X_{2}+\beta_{13} X_{1} X_{3} \\
& +\beta_{23} X_{2} X_{3}+\beta_{11} X_{1}^{2}+\beta_{22} X_{2}^{2}+\beta_{33} X_{3}^{2} \quad \text { (Equation 1) }
\end{aligned}
$$

where $\mathrm{Y}$ is the predicted response, $\mathrm{X}_{1}, \mathrm{X}_{2}$, and $\mathrm{X}_{3}$ are the independent variables, $\beta_{0}$ is the intercept, $\beta_{1}, \beta_{2}$, and $\beta_{3}$ represent linear coefficients, $\beta_{12}, \beta_{13}$, and $\beta_{23}$ represent interactive coefficients, $\beta_{11}, \beta_{22}$, and $\beta_{33}$ represent quadratic coefficients. The experimental results were analyzed using Matlab software (version 5.3, The Math Works Inc., Natick, MA, USA). Response surface plots were drawn to represent the interaction effects of the variables in the experiments. To search the optimal ratio of culture medium, an optimization program consisting of a multi-start SQP technique was coded to search for the global optimum. The program generates a series of uniformly distributed random points, with each point representing an initial design of the ratio of medial ingredients. Then SQP is applied to find the optimum based on each initial design. If the probability of the optimum being the global one exceeds a preset value ( $99.99 \%$ in this study), the global optimum is considered found. Otherwise, the next random initial design is generated and the SQP re-executed. Additionally, verification experiments were also conducted in triplicate under the optimal condition of the variables to confirm the 
Table 1. The experimental variables and responses of the Box-Behnken design

\begin{tabular}{|c|c|c|c|c|c|}
\hline \multirow[b]{2}{*}{ Run } & \multicolumn{3}{|c|}{ Variables } & \multicolumn{2}{|c|}{ Response (log CFU/mL) } \\
\hline & $\begin{array}{c}\mathrm{X}_{1} \text { : Soybean meal } \\
(\%, \mathrm{wt} / \mathrm{vol})\end{array}$ & $\begin{array}{c}\mathrm{X}_{2}: \text { Molasses } \\
(\%, \mathrm{wt} / \mathrm{vol})\end{array}$ & $\begin{array}{c}\mathrm{X}_{3} \text { : Sodium acetate } \\
(\%, \mathrm{wt} / \mathrm{vol})\end{array}$ & $x-1 d-2$ & $\mathrm{x}-4 \mathrm{w}-1$ \\
\hline 1 & $4.0(0)^{1}$ & $5.0(0)$ & $5.0(0)$ & 8.73 & 8.84 \\
\hline 2 & $5.5(1)$ & $5.0(0)$ & $1.0(1)$ & 8.81 & 9.20 \\
\hline 3 & $4.0(0)$ & $0(-1)$ & $0(-1)$ & 8.65 & 8.57 \\
\hline 4 & $2.5(-1)$ & $5.0(0)$ & $1.0(1)$ & 8.18 & 8.74 \\
\hline 5 & $2.5(-1)$ & $5.0(0)$ & $0(-1)$ & 8.20 & 8.59 \\
\hline 6 & $4.0(0)$ & $5.0(0)$ & $5.0(0)$ & 8.65 & 8.94 \\
\hline 7 & $4.0(0)$ & $5.0(0)$ & $5.0(0)$ & 8.65 & 8.94 \\
\hline 8 & $5.5(1)$ & $1.0(1)$ & $5.0(0)$ & 8.86 & 9.21 \\
\hline 9 & $2.5(-1)$ & $0(-1)$ & $5.0(0)$ & 8.17 & 8.22 \\
\hline 10 & $4.0(0)$ & $0(-1)$ & $1.0(1)$ & 8.48 & 8.70 \\
\hline 11 & $4.0(0)$ & $5.0(0)$ & $5.0(0)$ & 8.64 & 8.96 \\
\hline 12 & $4.0(0)$ & $1.0(1)$ & $1.0(1)$ & 8.71 & 9.13 \\
\hline 13 & $5.5(1)$ & $0(-1)$ & $5.0(0)$ & 8.61 & 8.91 \\
\hline 14 & $5.5(1)$ & $5.0(0)$ & $0(-1)$ & 8.61 & 8.99 \\
\hline 15 & $4.0(0)$ & $1.0(1)$ & $0(-1)$ & 8.65 & 8.84 \\
\hline 16 & $2.5(-1)$ & $1.0(1)$ & $5.0(0)$ & 8.53 & 8.97 \\
\hline 17 & $4.0(0)$ & $5.0(0)$ & $5.0(0)$ & 8.55 & 8.91 \\
\hline
\end{tabular}

${ }^{1}$ Values in parentheses indicated coded levels. The low, middle and high coded levels were designated as $-1,0$ and 1, respectively.

accuracy of the model in this study. The cell numbers of lactobacilli were determined by pour plating $(1.0 \mathrm{~mL})$ of diluted cells on lactobacilli MRS agar (BD Difco, USA). Viable colonies were counted after $24 \mathrm{~h}$ of incubation at $37^{\circ} \mathrm{C}$.

\section{Preparation of freeze-dried lactobacilli for the feeding trial}

L. johnsonii $\mathrm{x}-1 \mathrm{~d}-2$ and L. mucosae $\mathrm{x}-4 \mathrm{w}-1$ were grown at $37^{\circ} \mathrm{C}$ for $16 \mathrm{~h}$ in the estimated optimal medium $(5.5 \%$ (wt/vol) soybean meal, $1.0 \%$ (wt/vol) molasses and $1.0 \%$ (wt/vol) sodium acetate), respectively. Biomasses from optimal medium cultures were centrifuged at $3,000 \times \mathrm{g}$ for $10 \mathrm{~min}$ and freeze-dried under vacuum at $6.7 \mathrm{~Pa}$ for $24 \mathrm{~h}$ in a freeze-drier (Model 4.5, Labconco Crop., Kansas, MO, USA). The freeze-dried cultures of lactobacilli, which corresponded to ca. $10^{8} \mathrm{CFU} / \mathrm{g}$, were mixed with feed administered to animals during the feeding trial.

\section{Experimental animals, feeds and analyses}

A total of 24 LandracexDuroc crossbred piglets (12 males and 12 females) weaned at $21 \pm 3 \mathrm{~d}$ of age with an average weight of $6.77 \pm 0.37 \mathrm{~kg}$, obtained from Livestock Research Institute, Council of Agriculture, Executive Yuan (Tainan, Taiwan), were used in the experiments. The piglets were randomly distributed into 4 groups (6 piglets/group): i) control group (piglets fed basal diet); ii) J group (piglets fed basal diet supplemented with freeze-dried L. johnsonii $\mathrm{x}-1 \mathrm{~d}-2,10^{8} \mathrm{CFU} / \mathrm{g}$ per piglet per d); iii) $\mathrm{M}$ group (piglets fed basal diet supplemented with freeze-dried L. mucosae $\mathrm{x}-$
$4 \mathrm{w}-1,10^{8} \mathrm{CFU} / \mathrm{g}$ per piglet per d); and iv) JM group (piglets fed basal diet supplemented with freeze-dried $L$. johnsonii $\mathrm{x}-1 \mathrm{~d}-2,5 \times 10^{7} \mathrm{CFU} / \mathrm{g}$ and L. mucosae $\mathrm{x}-4 \mathrm{w}-1$, $5 \times 10^{7} \mathrm{CFU} / \mathrm{g}$ per piglet per $\left.\mathrm{d}\right)$. The basal diet consisted of yellow corn $(67.7 \%, \mathrm{wt} / \mathrm{wt})$, soybean meal $(19.0 \%, \mathrm{wt} / \mathrm{wt})$, fish meal $(5.0 \%, \mathrm{wt} / \mathrm{wt})$, skim milk powder $(2.0 \% \mathrm{wt} / \mathrm{wt})$, whey power $(2.0 \%, \mathrm{wt} / \mathrm{wt})$, dicalcium phosphate $(1.6 \%$, $\mathrm{wt} / \mathrm{wt})$, soybean oil $(1.0 \%, \mathrm{wt} / \mathrm{wt})$, calcium carbonate $(0.8 \%$ $\mathrm{wt} / \mathrm{wt})$, salt $(0.5 \%, \mathrm{wt} / \mathrm{wt})$, mineral premix $(0.15 \%, \mathrm{wt} / \mathrm{wt})$, vitamin premix $(0.1 \%$, wt/wt), choline $(0.1 \%, \mathrm{wt} / \mathrm{wt})$ and copper sulphate $(0.04 \%, \mathrm{wt} / \mathrm{wt})$. Each group was separately housed in an individual cage and randomly fed basal diet or diet supplemented with freeze-dried probiotic strains for 21 $\mathrm{d}$ at ambient room temperatures $\left(22\right.$ to $\left.27^{\circ} \mathrm{C}\right)$ and 50 to $60 \%$ relative humidity. Body weight gain (BWG), feed intake (FI), gain/feed ratio, and lactobacilli and E. coli counts in the feces were measured for each piglet after different periods of the feeding trial, respectively. Animal experiment followed the Guide for the Care and Use of Laboratory Animals in Taiwan.

\section{Detection of lactobacilli and $E$. coli in the feces of weaned piglets}

The fresh feces were taken from the rectum of weaned piglets with a sterile cotton swab. Approximately $1.0 \mathrm{~g}$ of fecal sample was serially diluted in $0.85 \%$ (wt/vol) saline and then pour plated $(1.0 \mathrm{~mL})$ on Lactobacillus selective Agar Base (Acumedia, Baltimore, MD, USA) and CHROMagar ECC (CHROMagar Microbiology, Paris, France) for lactobacilli and $E$. coli, respectively. The 
numbers of viable colonies on triplicate plates were counted after incubation at $37^{\circ} \mathrm{C}$ for $48 \mathrm{~h}$.

\section{Statistical analysis}

All replicate experiments were executed independently. The data were analyzed with the general linear model procedures of SAS statistical software (SAS Institute, Cary, NC, USA). Significant differences $(p<0.05)$ between treatment means were determined using Tukey's pair-wise comparison test (except RSM study).

\section{RESULTS AND DISCUSSION}

\section{Optimization of growth medium for production of} probiotic strains

In the preliminary experiment, several nitrogen sources (brewer's yeast, sugar yeast, soybean meal and whey protein) and carbon sources (glucose, lactose, sucrose, and molasses) were tested. We found that soybean meal and molasses were the most economical and effective ingredients for the growth of $L$. johnsonii $\mathrm{x}-1 \mathrm{~d}-2$ and $L$. mucosae $\mathrm{x}-4 \mathrm{w}-1$ compared with other nitrogen and carbon sources (data not shown). Moreover, the addition of sodium acetate into the medium also promoted the growth of the two probiotic strains (data not shown). Considering the material cost and the growth of lactobacilli, soybean meal, molasses and sodium acetate were used for components to develop a low-cost culture medium for mass production of L. johnsonii $\mathrm{x}-1 \mathrm{~d}-2$ and L. mucosae $\mathrm{x}-4 \mathrm{w}-1$ in this study.

The results for the growth of $L$. johnsonii $\mathrm{x}-1 \mathrm{~d}-2$ and $L$. mucosae $\mathrm{x}-4 \mathrm{w}-1$ were used to build the response surface model according to the BBD presented in Table 1 . The analysis of variance for the BBD in Table 2 showed that the quadratic and 2FI models, suggested by model analysis and lack-of-fit test, were well suited to represent the experimental data of L. johnsonii x-1d-2 and L. mucosae $\mathrm{x}-$ $4 \mathrm{w}-1$ with determination coefficients $\left(\mathrm{R}^{2}\right)$ of 0.92 and 0.94 , respectively. The polynomial regression models obtained for $L$. johnsonii $\mathrm{x}-1 \mathrm{~d}-2$ and $L$. mucosae $\mathrm{x}-4 \mathrm{w}-1$ were as follows:

$$
\begin{aligned}
\mathrm{Y}_{\mathrm{x}-1 \mathrm{~d}-2}= & 7.06+0.62 \mathrm{X}_{1}+0.10 \mathrm{X}_{2}-0.16 \mathrm{X}_{3} \\
& -0.04 \mathrm{X}_{1} \mathrm{X}_{2}+0.07 \mathrm{X}_{1} \mathrm{X}_{3}+0.23 \mathrm{X}_{2} \mathrm{X}_{3} \\
& -0.06 \mathrm{X}_{1}^{2}+0.14 \mathrm{X}_{2}^{2}-0.23 \mathrm{X}_{3}^{2} \quad \text { (Equation 2) } \\
\mathrm{Y}_{\mathrm{x}-4 \mathrm{w}-1}= & 7.73+0.21 \mathrm{X}_{1}+0.96 \mathrm{X}_{2}+0.04 \mathrm{X}_{3}-0.15 \mathrm{X}_{1} \mathrm{X}_{2} \\
+ & 0.02 \mathrm{X}_{1} \mathrm{X}_{3}+0.16 \mathrm{X}_{2} \mathrm{X}_{3} \quad \text { (Equation 3) }
\end{aligned}
$$

To depict the optimization results, a 3-D response surface plot was generated by fixing two of the three variables as shown in Figure 1. The SQP was applied to search the optimal ratio of growth medium for maximum cultivation of $L$. johnsonii $\mathrm{x}-1 \mathrm{~d}-2$ and L. mucosae $\mathrm{x}-4 \mathrm{w}-1$. The greatest population of $L$. johnsonii x-1d-2 (8.90 log $\mathrm{CFU} / \mathrm{mL})$ and L. mucosae $\mathrm{x}-4 \mathrm{w}-1$ (9.30 $\log \mathrm{CFU} / \mathrm{mL})$ was attained with the optimal points $\mathrm{X}_{1}$ (soybean meal) $=5.5 \%$ $(\mathrm{wt} / \mathrm{vol}), \mathrm{X}_{2}$ (molasses) $=1.0 \%(\mathrm{wt} / \mathrm{vol})$ and $\mathrm{X}_{3}$ (sodium acetate $)=1.0 \%(\mathrm{wt} / \mathrm{vol})$. The optimal medium ratio for maximum production of $L$. johnsonii $\mathrm{x}-1 \mathrm{~d}-2$ and $L$. mucosae $\mathrm{x}-4 \mathrm{w}-1$ derived from the SQP scheme was further verified by an additional experiment. In this study, the experimental values were very close to the predicted values (Table 3). Additionally, the bacterial numbers of the two probiotic strains cultured in the optimal medium were similar to those grew in MRS broth after incubation for $16 \mathrm{~h}$ (data not shown). These results indicated that the growth of L. johnsonii $\mathrm{x}-1 \mathrm{~d}-2$ and $L$. mucosae $\mathrm{x}-4 \mathrm{w}-1$ can be effectively increased using the optimal culture medium. Similar studies on the application of RSM reported that optimization of medium composition improved the productivity of probiotic L. fermentum and L. salivarius (Lim et al., 2007; Gao et al., 2009). However, to the best of our knowledge, this study is the first report on the

\begin{tabular}{|c|c|c|c|c|c|c|}
\hline \multirow{2}{*}{ Strain } & \multirow{2}{*}{ Source } & \multicolumn{2}{|c|}{ Model } & \multicolumn{2}{|c|}{ Lack-of-fit } & \multirow{2}{*}{$\mathrm{R}$ square } \\
\hline & & Sum of squares & $\mathrm{p}$-value & Sum of squares & p-value & \\
\hline \multirow[t]{5}{*}{$x-1 d-2$} & Mean & $1,248.39$ & & & & \\
\hline & Linear & 0.50 & 0.0005 & 0.17 & 0.08 & \\
\hline & Two-factor interaction & 0.03 & 0.62 & 0.14 & 0.06 & \\
\hline & Quadratic & 0.10 & $0.05^{*}$ & 0.04 & $0.15^{* *}$ & 0.92 \\
\hline & Cubic & 0.04 & 0.15 & 0.00 & & \\
\hline \multirow[t]{5}{*}{$x-4 w-1$} & Mean & $1,335.20$ & & & & \\
\hline & Linear & 0.86 & $<0.0001$ & 0.11 & 0.06 & \\
\hline & Two-factor interaction & 0.06 & $0.06^{*}$ & 0.05 & $0.11 * *$ & 0.94 \\
\hline & Quadratic & 0.03 & 0.10 & 0.02 & 0.20 & \\
\hline & Cubic & 0.02 & 0.20 & 0.00 & & \\
\hline
\end{tabular}
optimization of growth medium for cultivation of $L$. johnsonii and L. mucosae using RSM and SQP.

Soybean meal and molasses are by-products of soybean

Table 2. Analysis of variance for the results of the Box-Behnken design

\footnotetext{
* Suggested by model analysis which selected the highest order polynomial where the additional terms were significant and the model was not aliased
}

** Suggested by lack-of-fit test which wanted the selected model to have insignificant lack-of-fit. Statistical significance was set at p<0.05 by t-test. 


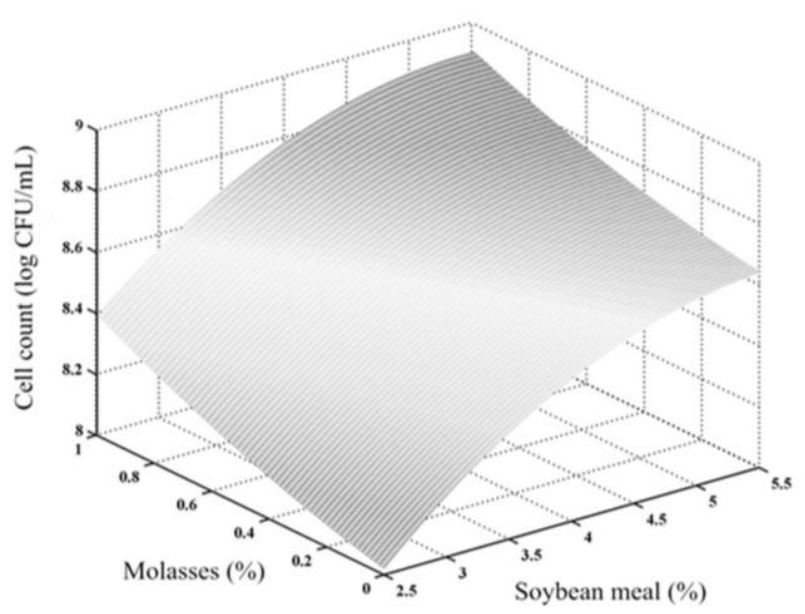

(a)

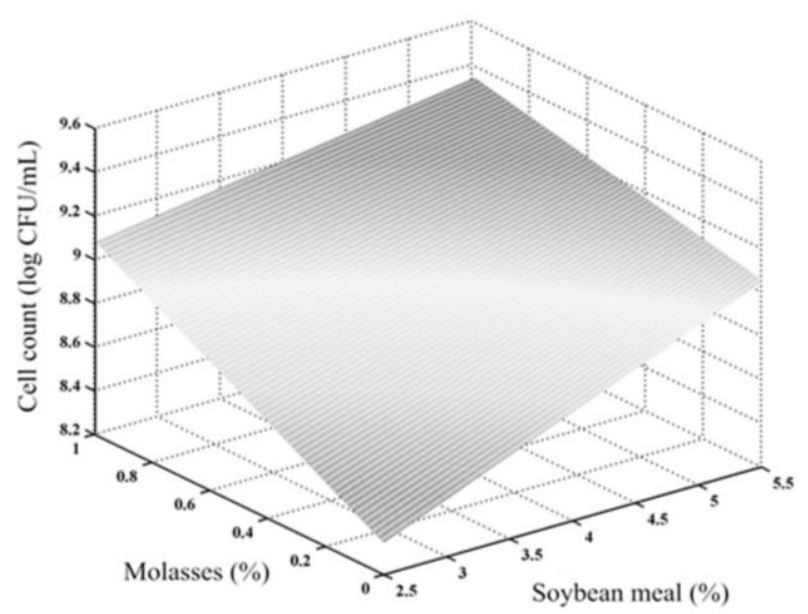

(b)

Figure 1. Surface response plots of the interaction effects of soybean meal and molasses on the growth of $L$. johnsonii $\mathrm{x}-1 \mathrm{~d}-2$ (a) and $L$. mucosae $\mathrm{x}-4 \mathrm{w}-1$ (b). Sodium acetate concentration was set at $1.0 \%(\mathrm{wt} / \mathrm{vol})$.

Table 3. Predicted and experimental values of population under optimal medium composition

\begin{tabular}{|c|c|c|c|c|c|}
\hline \multirow{2}{*}{ Strain } & \multicolumn{3}{|c|}{ Optimal medium composition $(\%, \mathrm{wt} / \mathrm{vol})$} & \multicolumn{2}{|c|}{ Cell count $(\log \mathrm{CFU} / \mathrm{mL})$} \\
\hline & Soybean meal & Molasses & Sodium acetate & Predicted value $^{1}$ & Experimental value $^{2}$ \\
\hline$x-1 d-2$ & 5.5 & 1.0 & 1.0 & 8.90 & 8.81 \\
\hline$x-4 w-1$ & 5.5 & 1.0 & 1.0 & 9.30 & 9.19 \\
\hline
\end{tabular}

${ }^{1}$ Predicted values were calculated from the regression models.

${ }^{2}$ Experimental values were means obtained from the verification experiments.

industry and sugar manufacturing process, respectively. Soybean meal is an important source of protein widely used in farm animal diets (Cromwell et al., 1999). Its mean value of protein is above $45.0 \%(\mathrm{wt} / \mathrm{wt})$. Molasses contains significant amounts of sucrose, glucose and fructose with several essential nutrients such as vitamins, minerals and other organic compounds (Makkar and Cameotra, 2002). Recent studies have shown that inexpensive soybean and molasses can be used as primary nitrogen and carbon sources to replace the costly yeast extract and other conventional sugars for the production of some microorganisms, including Bacillus and Lactobacillus spp. (Saha, 2006; Tari et al., 2006). Besides, sodium acetate, a basic component of commercial MRS medium, is known as an energy source as well as selective agent for lactobacilli (Stiles et al., 2002). After calculation, the cost of the optimal medium (ca. USD \$0.3/L) was $96 \%$ lower than the commercial MRS medium (ca. USD \$8/L). Once developing a low-cost culture medium, we massed production of two probiotic strains, L. johnsonii x-1d-2 and L. mucosae $\mathrm{x}-4 \mathrm{w}-1$, and made the probiotic powders by freeze drying for the following animal study.

\section{Growth performance of weaned piglets fed probiotic} strains

The effect of probiotic feeding on the growth performance of weaned piglets is presented in Table 4. All piglets kept healthy and no deaths occurred during the feeding trials. The initial body weight (BW) of piglets showed no difference ( $p>0.05)$ among all groups. After $21-d$ probiotic feeding, the final BW was significantly higher $(\mathrm{p}<0.05)$ in piglets fed basal diet supplemented with freezedried probiotic cultures (L. johnsonii x-1d-2 (J) group, $L$. mucosae $\mathrm{x}-4 \mathrm{w}-1$ (M) group and mixed-strain (JM) group) than in piglets fed basal diet (control group). The BWG values were significantly increased $(\mathrm{p}<0.05)$ for feeding with L. mucosae $\mathrm{x}-4 \mathrm{w}-1$ (M group), followed by JM, J, and control groups. Higher FI was observed in piglets of J, M, and JM groups than in control group. Addotionally, the probiotic treated groups showed a significantly higher $(\mathrm{p}<$ $0.05)$ gain/feed ratio than the control group. The piglets fed with $L$. mucosae $\mathrm{x}-4 \mathrm{w}-1$ had the best feed efficiency. These results showed that addition of $L$. johnsonii $\mathrm{x}-1 \mathrm{~d}-2$ and $L$. mucosae $\mathrm{x}-4 \mathrm{w}-1$ to the basal diet improved the growth performance of weaned piglets.

Similar studies have used Lactobacillus spp., including L. reuteri (Chang et al., 2001), L. casei subsp. casei (Guerra et al., 2007), L. fermentum (Yu et al., 2008) and L. sobrius (Konstantinov et al., 2008) to improve the growth performance of piglets. In this study, L. johnsonii x-1d-2 and $L$. mucosae $\mathrm{x}-4 \mathrm{w}-1$, originally isolated from piglet feces, are believed to be able to colonize and survive in the 
Table 4. Growth performance of weaned piglets after feeding for $21 \mathrm{~d}$

\begin{tabular}{|c|c|c|c|c|c|c|}
\hline \multirow{2}{*}{ Item $^{2}$} & \multicolumn{4}{|c|}{ Treatment $^{1}$} & \multirow{2}{*}{ SEM } & \multirow{2}{*}{ p-value } \\
\hline & Control & $\mathrm{J}$ & M & JM & & \\
\hline Initial $\mathrm{BW}^{2}(\mathrm{~kg} /$ piglet $)$ & 6.80 & 6.88 & 6.65 & 6.74 & 0.11 & 0.92 \\
\hline Final BW (kg/piglet) & $12.79^{\mathrm{a}}$ & $14.70^{\mathrm{b}}$ & $16.81^{\mathrm{c}}$ & $15.97^{\mathrm{bc}}$ & 0.49 & 0.0005 \\
\hline BWG (kg/piglet) & $6.00^{\mathrm{a}}$ & $7.82^{\mathrm{b}}$ & $10.16^{\mathrm{c}}$ & $9.23^{\mathrm{c}}$ & 0.48 & $<0.0001$ \\
\hline FI (kg/piglet) & $13.20^{\mathrm{a}}$ & $14.47^{\mathrm{b}}$ & $15.43^{\mathrm{bc}}$ & $15.70^{\mathrm{c}}$ & 0.32 & 0.0006 \\
\hline Gain/feed ratio & $0.45^{\mathrm{a}}$ & $0.54^{\mathrm{b}}$ & $0.66^{\mathrm{c}}$ & $0.59^{\mathrm{b}}$ & 0.02 & $<0.0001$ \\
\hline
\end{tabular}

SEM, standard error of the mean.

${ }^{1} \mathrm{n}=6$, control, fed basal diet; J, supplemented with L. johnsonii $\mathrm{x}-1 \mathrm{~d}-2$; M, supplemented with L. mucosae $\mathrm{x}-4 \mathrm{w}-1$; JM, supplemented with L. johnsonii $\mathrm{x}-1 \mathrm{~d}-2$ and L. mucosae $\mathrm{x}-4 \mathrm{w}-1$.

${ }^{2}$ Initial BW, initial body weight on d 0 ; final BW, final body weight on d 21; BWG, body weight gain during d 0 to 21 ; FI, feed intake during d 0 to 21; gain/feed ratio was calculated as BWG divided by FI.

${ }^{a, b, c}$ Means in the same row with different superscript letters are significantly different $(\mathrm{p}<0.05)$.

intestine to exert the desirable effects. Van Tassell and Miller (2011) reported that the probiotic properties of lactobacilli are mainly from adhesion to the gastrointestinal tract, competition exclusion against pathogens and production of antimicrobial compounds. The features of $L$. johnsonii $\mathrm{x}-1 \mathrm{~d}-2$ and $L$. mucosae $\mathrm{x}-4 \mathrm{w}-1$ might provide a beneficial effect on the maintenance of intestinal microflora balance in weaned piglets.

Lactobacilli and $E$. coli counts in the feces of weaned piglets fed probiotic strains

The data on viable counts of lactobacilli and E. coli in the feces of weaned piglets during 21-d feeding are shown in Table 5. The viable counts of lactobacilli in the feces of probiotic (J, M, and JM) groups increased as the feeding period was extended, whereas lactobacilli counts remain constant in non-probiotic (control) group during feeding. After a 21-d feeding period, piglet feces from probiotic groups contained significantly higher $(\mathrm{p}<0.05)$ lactobacilli counts compared with control group. The greatest lactobacilli numbers were observed in $\mathbf{M}$ group, followed by JM and $\mathrm{J}$ groups, with a bacterial population of 8.25 , 8.13, and $7.76 \log \mathrm{CFU} / \mathrm{g}$, respectively. On the other hand, during the 21-d feeding, a reduction of $0.56,0.23$, and 0.47 $\log$ CFU/g in E. coli counts was observed in J, M, and JM groups, respectively. At the end of feeding, the numbers of E. coli were significantly lower $(\mathrm{p}<0.05)$ in probiotic groups than in control group. This study showed that probiotic feeding (L. johnsonii $\mathrm{x}-1 \mathrm{~d}-2$ and $L$. mucosae $\mathrm{x}-$ 4 w-1) could decrease the $E$. coli population and increase the lactobacilli population in the intestinal tract of weaned piglets.

The results suggested that the improvement of weaned piglet growth performance might likely be the effect of $L$. johnsonii $\mathrm{x}-1 \mathrm{~d}-2$ and $L$. mucosae $\mathrm{x}-4 \mathrm{w}-1$ on the intestinal microbial ecosystem. It is worth noting that weaned piglets

Table 5. Viable counts of lactobacilli and E. coli in the feces of weaned piglets during 21-d feeding

\begin{tabular}{|c|c|c|c|c|c|c|}
\hline \multirow{2}{*}{ Time (d) } & \multicolumn{4}{|c|}{ Treatment $^{1}$} & \multirow{2}{*}{ SEM } & \multirow{2}{*}{ p-value } \\
\hline & Control & $\mathrm{J}$ & $\mathrm{M}$ & JM & & \\
\hline \multicolumn{7}{|c|}{ Lactobacilli (log CFU/g) } \\
\hline 0 & 6.20 & $6.38^{x}$ & $6.45^{\mathrm{x}}$ & $6.28^{\mathrm{x}}$ & 0.09 & 0.80 \\
\hline 7 & 6.36 & $6.73^{x y}$ & $7.02^{x y}$ & $6.78^{x y}$ & 0.12 & 0.33 \\
\hline 14 & $6.33^{\mathrm{a}}$ & $7.35^{\mathrm{b}, \mathrm{yz}}$ & $7.59^{\mathrm{b}, \mathrm{yz}}$ & $7.41^{\mathrm{b}, \mathrm{yz}}$ & 0.18 & 0.01 \\
\hline 21 & $6.17^{\mathrm{a}}$ & $7.76^{\mathrm{b}, \mathrm{z}}$ & $8.25^{\mathrm{b}, \mathrm{z}}$ & $8.13^{\mathrm{b}, \mathrm{z}}$ & 0.26 & $<0.0001$ \\
\hline SEM & 0.09 & 0.18 & 0.22 & 0.23 & & \\
\hline p-value & 0.89 & 0.002 & 0.0005 & 0.003 & & \\
\hline \multicolumn{7}{|c|}{ E. coli $(\log \mathrm{CFU} / \mathrm{g})$} \\
\hline 0 & 5.75 & $5.84^{x y}$ & 5.72 & 5.87 & 0.09 & 0.96 \\
\hline 7 & 5.80 & $6.08^{x}$ & 5.78 & 5.71 & 0.08 & 0.38 \\
\hline 14 & 5.90 & $5.76^{\mathrm{xy}}$ & 5.65 & 5.64 & 0.08 & 0.71 \\
\hline 21 & $6.14^{\mathrm{a}}$ & $5.28^{\mathrm{b}, \mathrm{y}}$ & $5.49^{\mathrm{ab}}$ & $5.40^{\mathrm{ab}}$ & 0.12 & 0.03 \\
\hline SEM & 0.10 & 0.11 & 0.09 & 0.07 & & \\
\hline p-value & 0.60 & 0.05 & 0.78 & 0.16 & & \\
\hline
\end{tabular}

SEM, standard error of the mean.

${ }^{1} \mathrm{n}=6$, control, fed basal diet; J, supplemented with L. johnsonii x-1d-2; M, supplemented with L. mucosae x-4w-1; JM, supplemented with L. johnsonii $\mathrm{x}-1 \mathrm{~d}-2$ and L. mucosae $\mathrm{x}-4 \mathrm{w}-1$.

${ }^{a, b}$ Means in the same row with different superscript letters are significantly different $(\mathrm{p}<0.05)$.

${ }^{x, y, z}$ Means in the same column with different superscript letters are significantly different $(\mathrm{p}<0.05)$. 
fed with $L$. mucosae $\mathrm{x}-4 \mathrm{w}-1$ showed the best growth performance and greatest number of lactobacilli among the probiotic treatments. Furthermore, indigenous lactobacilli have been implicated in the suppression of intestinal colonization potential of E. coli (Blomberg et al., 1993). Being the most common bacterial microflora of the gut, $E$. coli is one of major reason causing piglet diarrhea, which could affect the intestinal barrier and cause disturbed integrity (Liu et al., 2008). This indicates that high concentration of lactobacilli and reduced population of $E$. coli in the intestinal tract might decrease the incidence and score of diarrhea.

The adhesion of probiotic lactobacilli to intestinal mucus makes them colonize the gut efficiently and settle down to a stable population, that may provide health benefit and avoid infectious disease for piglet ( $\mathrm{Li}$ et al., 2008). In addition, a number of studies have identified various cellsurface proteins such as mucus-binding proteins, adhesionlike proteins, fimbrial subunits, elongation factor, and heat shock GroEL protein in L. johnsonii and L. mucosae. These proteins were stated to be involved in bacterial adhesion to intestinal mucosa, protection against pathogen colonization, and immune system stimulation (Roos et al., 2000; Granato et al., 2004; Pridmore et al., 2004; Bergonzelli et al., 2006; Watanabe et al., 2010). The possible mechanisms of improvement of piglet growth performance in this study may be related to the adhesive, antimicrobial and immunomodulatory activities of $L$. johnsonii $\mathrm{x}-1 \mathrm{~d}-2$ and $L$. mucosae $\mathrm{x}-4 \mathrm{w}-1$. Therefore, we suggest that these two probiotic strains have high potential to be used as feed additives for weaned piglets.

\section{CONCLUSION}

In the present study, we successfully developed a lowcost medium for mass production of $L$. johnsonii $\mathrm{x}-1 \mathrm{~d}-2$ and L. mисоsae $\mathrm{x}-4 \mathrm{w}-1$ isolated from piglet feces. Further animal trials showed that administration of these two probiotic strains could improve the growth performance and intestinal microflora in weaned piglets. This study provides evidences for two novel indigenous strains, $L$. johnsonii $\mathrm{x}$ $1 \mathrm{~d}-2$ and $L$. mисоsae $\mathrm{x}-4 \mathrm{w}-1$, which have high potential to be used as feed additives in the pig industry.

\section{ACKNOWLEDGMENTS}

This research was funded by a project of Council of Agriculture, Executive Yuan (Taipei, Taiwan).

\section{REFERENCES}

Berg, R. D. 1995. Bacterial translocation from the gastrointestinal tract. Trends Microbiol. 3:149-154.
Bergonzelli, G. E., D. Granato, R. D. Pridmore, L. F. Marvin-Guy, D. Donnicola, and I. E. Corthésy-Theulaz. 2006. GroEL of Lactobacillus johnsonii La1 (NCC 533) is cell surface associated: Potential role in interactions with the host and the gastric pathogen Helicobacter pylori. Infect. Immun. 74:425434.

Blomberg, L., A. Henriksson, and P. L. Conway. 1993. Inhibition of adhesion of Escherichia coli K88 to piglet ileal mucus by Lactobacillus spp. Appl. Environ. Microbiol. 59:34-39.

Box, G. E. P. and D. W. Behnken. 1960. Some new three level designs for the study of quantitative variables. Technometrics 2:455-475

Casewell, M., C. Friis, E. Marco, P. Mcmullin, and I. Phillips. 2003. The European ban on growth-promoting antibiotics and emerging consequences for human and animal health. J. Antimicrob. Chemother. 52:159-161.

Casey, P. G., G. D. Casey, G. E. Gardiner, M. Tangney, C. Stanton, R. P. Ross, C. Hill, and G. F. Fitzgerald. 2004. Isolation and characterization of anti-Salmonella lactic acid bacteria from the porcine gastrointestinal tract. Lett. Appl. Microbiol. 39:431-438.

Chang, Y. H., J. K. Kim, H. J. Kim, W. Y. Kim, Y. B. Kim, and Y. H. Park. 2001. Selection of a potential probiotic Lactobacillus strain and subsequent in vivo studies. Antonie Van Leeuwenhoek 80:193-199.

Chen, Y. P., P. J. Hsiao, W. S. Hong, T. Y. Dai, and M. J. Chen. 2012. Lactobacillus kefiranofaciens M1 isolated from milk kefir grains ameliorates experimental colitis in vitro and in vivo. J. Dairy. Sci. 95:63-74.

Cromwell, G. L., C. C. Calvert, T. R. Cline, J. D. Crenshaw, T. D. Crenshaw, R. A. Easter, R. C. Ewan, C. R. Hamilton, G. M. Hill, A. J. Lewis, D. C. Mahan, E. R. Miller, J. L. Nelssen, J. E Pettigrew, L. F. Trible, T. L. Veum, and J. T. Yen. 1999. Variability among sources and laboratories in nutrient analyses of corn and soybean meal. J. Amim. Sci. 77:3262-3273.

Flint, J. F. and M. R. Garner. 2009. Feeding beneficial bacteria: A natural solution for increasing efficiency and decreasing pathogens in animal agriculture. J. Appl. Poult. Res. 18:367378.

Gao, X., S. Y. Qiao, and W. Q. Lu. 2009. Determination of an economical medium for growth of Lactobacillus fermentum using response surface methodology. Lett. Appl. Microbiol. 49:556-561.

Granato, D., G. E. Bergonzelli, R. D. Pridmore, L. Marvin, M. Rouvet, and I. E. Corthésy-Theulaz. 2004. Cell surfaceassociated elongation factor Tu mediates the attachment of Lactobacillus johnsonii NCC533 (La1) to human intestinal cells and mucins. Infect. Immun. 72:2160-2169.

Guerra, N. P., P. F. Bernárdez, J. Méndez, P. Cachaldora, and L. P. Castro. 2007. Production of four potentially probiotic lactic acid bacteria and their evaluation as feed additives for weaned piglets. Anim. Feed Sci. Technol. 134:89-107.

Konstantinov, S. R., H. Smidt, A. D. L. Akkermans, L. Casini, P. Trevisi, M. Mazzoni, S. De Filippi, P. Bosi, and W. M. de Vos. 2008. Feeding of Lactobacillus sobrius reduces Escherichia coli F4 levels in the gut and promotes growth of infected piglets. FEMS Microbiol. Ecol. 66:599-607.

La Ragione R. M., A. Narbad, M. J. Gasson, and M. J. Woodward. 
2004. In vivo characterization of Lactobacillus johnsonii FI9785 for use as a defined competitive exclusion agent against bacterial pathogens in poultry. Lett. Appl. Microbiol. 38:197-205.

Lee, J. H., V. D. Valeriano, Y. R. Shin, J. P. Chae, G. B. Kim, J. S. Ham, J. Chun, and D. K. Kang. 2012. Genome sequence of Lactobacillus mucosae LM1, isolated from piglet feces. J. Bacteriol. 194:4766.

Li, X. J., L. Y. Yue, X. F. Guan, and S. Y. Qiao. 2008. The adhesion of putative probiotic lactobacilli to cultured epithelial cells and porcine intestinal mucus. J. Appl. Microbiol. 104:1082-1091.

Lim, C. H., R. A. Rahim, Y. W. Ho, and B. A. Arbakariya. 2007. Optimization of growth medium for efficient cultivation of Lactobacillus salivarius i 24 using response surface method. Malaysian J. Microbiol. 3:41-47.

Liu, P., X. S. Piao, S. W. Kim, L. Wang, Y. B. Shen, H. S. Lee, and S. Y. Li. 2008. Effects of chito-oligosaccharide supplementation on the growth performance, nutrient digestibility, intestinal morphology, and fecal shedding of Escherichia coli and Lactobacillus in weaning pigs. J. Anim. Sci. 86:2609-2618.

Makkar, R. S. and S. S. Cameotra. 2002. An update on the use of unconventional substrates for biosurfactant production and their new applications. Appl. Microbiol. Biotechnol. 58:428434

Meng, Q. W., L. Yan, X. Ao, T. X. Zhou, J. P. Wang, J. H. Lee, and I. H. Kim. 2010. Influence of probiotics in different energy and nutrient density diets on growth performance, nutrient digestibility, meat quality, and blood characteristics in growing-finishing pigs. J. Anim. Sci. 88:3320-3326.
Pridmore, R. D., B. Berger, F. Desiere, D. Vilanova, C. Barretto, A. C. Pittet, M. C. Zwahlen, M. Rouvet, E. Altermann, R. Barrangou, B. Mollet, A. Mercenier, T. Klaenhammer, F. Arigoni, and M. A. Schell. 2004. The genome sequence of the probiotic intestinal bacterium Lactobacillus johnsonii NCC 533. Proc. Natl. Acad. Sci. USA 101:2512-2517.

Roos, S., F. Karner, L. Axelsson, and H. Jonsson. 2000. Lactobacillus mucosae sp. nov., a new species with in vitro mucus-binding activity isolated from pig intestine. Int. J. Syst. Evol. Microbiol. 50:251-258.

Saha, B. C. 2006. A low-cost medium for mannitol production by Lactobacillus intermedius NRRL B-3693. Appl. Microbiol. Biotechnol. 72:676-680.

Stiles, J., S. Penkar, M. Plocková, J. Chumchalová, and L. B. Bullerman. 2002. Antifungal activity of sodium acetate and Lactobacillus rhamnosus. J. Food Prot. 65:1188-1191.

Tari, C., H. Gencjal, and F. Tokatl1. 2006. Optimization of a growth medium using a statistical approach for the production of an alkaline protease from a newly isolated Bacillus sp. L21. Proc. Biochem. 41:659-665.

Van Tassell, M. L. and M. J. Miller. 2011. Lactobacillus adhesion to mucus. Nutrients 3:613-636.

Watanabe, M., H. Kinoshita, M. Nitta, R. Yukishita, Y. Kawai, K. Kimura, N. Taketomo, Y. Yamazaki, Y. Tateno, K. Miura, A. Horii, H. Kitazawa, and T. Saito. 2010. Identification of a new adhesin-like protein from Lactobacillus mucosae ME-340 with specific affinity to the human blood group A and B antigens. J. Appl. Microbiol. 109:927-935.

Yu, H. F., A. N. Wang, X. J. Li, and S. Y. Qiao. 2008. Effect of viable Lactobacillus fermentum on the growth performance, nutrient digestibility and immunity of weaned pigs. J. Anim. Feed Sci. 17:61-69. 